\title{
Produção e qualidade do meloeiro cultivado com filmes plásticos em respostas à lâmina de irrigação ${ }^{1}$
}

\author{
Yield and quality of the melon fruit grown with plastic films in response to irrigation \\ depth
}

\author{
Daniel da Costa Dantas ${ }^{2 *}$, José Francismar de Medeiros ${ }^{3}$ e Alcione Guimarães Freire ${ }^{4}$
}

\begin{abstract}
Resumo - A demanda por técnicas que aumentem a produtividade do melão e proporcionem a padronização dos frutos nas características desejáveis pelos consumidores como, elevado teor de sólidos solúveis e firmeza de polpa, bom sabor e boa aparência externa, é uma realidade. A cobertura do solo com filmes plásticos é uma técnica que foi introduzida no agro-pólo Assu-Mossoró-Baraúna para suprir essa demanda. Por outro lado, o uso de cobertura do solo com filmes plásticos modifica a evapotranspiração das áreas cultivadas, necessitando de ajustes da lâmina de irrigação. Objetivou-se com este trabalho avaliar o efeito de quatro lâminas de irrigação (L1 -100\%; L2 - 91\%; L3 - 82\% e L4 - 72\% da lâmina padrão de 452 mm, a qual foi determinada pela metodologia do Kc dual da FAO) e três tipos de filmes de polietileno (branco-preto, prata-preto e preto-preto) na cobertura do solo, comparando com o cultivo sem cobertura, na produção e qualidade dos frutos do meloeiro. A utilização dos filmes de polietileno proporcionou um aumento expressivo na produtividade, sendo o aumento no peso dos frutos de $20 \%$ em média em relação ao tratamento com solo descoberto; os filmes de polietileno de coloração branco-preto e pretopreto sobressaíram em relação ao de cor prata-preto; a lâmina padrão de $452 \mathrm{~mm}$ pode ser reduzida em até $28 \%$ sem alterar a produção mesmo havendo redução do peso médio dos frutos em $11 \%$; a concentração de sólidos solúveis diminuiu à medida que a lâmina de irrigação foi reduzida, devido ao intenso ataque de pragas.
\end{abstract}

Palavras-chave - Cucumis melo. Mulching. Irrigação.

\begin{abstract}
The need for techniques that increase the yield of melon with fruit in obtaining desirable traits by consumers, with high content of soluble solids and pulp firmness, good flavor and good external appearance, is a reality. The soil cover with polyethylene films is a technique that was introduced in the agro-pole Assu-Mossoró-Baraúna to meet this demand. The objective of this study was to evaluate the yield and fruit quality of yellow melon grown with four irrigation depths (L1 $100 \%$, L2 - 91\%, L3 - 82\%, L4 - 72\% of the standard depth of $452 \mathrm{~mm}$ which was determined by the methodology of the FAO $\mathrm{Kc}$ dual) and tree types of polyethylene film (white-black, silver-black, black-black) used for the soil cover, compared with cultivation without coverage. Was used the randomized block design with split plot into $4 \times 4$, and four replications. The use of polyethylene films provided a significant increase in yield, and the increase of fruit weight by $20 \%$ on average, compared to treatment without coverage; the polyethylene film of white-black and black-black were better in relation to the silver-black color; the standard depth of $452 \mathrm{~mm}$ can be reduced by $28 \%$ without yield reduction even with the average fruit weight decrease by $11 \%$; the concentration of soluble solids decreased as the irrigation was reduced due to heavy pest attack.
\end{abstract}

Key words - Cucumis melo. Mulching. Irrigation.

\footnotetext{
*Autor para correspondência

${ }^{1}$ Recebido para publicação em 11/05/2010; aprovado em 06/04/2011

Trabalho financiado pela Eletroplastic ${ }^{\circledR}$, em convênio com a Fundação Guimarães Duque

${ }^{2}$ Programa de Pós-graduação em Irrigação e Drenagem, UFERSA, Av. Caxangá, 5671, bloco H, apto 302, 50.740-000, Recife-PE, Brasil, d1cdantas@hotmail.com

${ }^{3}$ Universidade Federal Rural do Semi-Árido/UFERSA, BR 110, km 47, Costa e Silva, 59.625-900, Mossoró-RN, Brasil, jfmedeir@ufersa.edu.br

${ }^{4}$ Programa de Pós-graduação em Ciência do Solo, Universidade Federal do Ceará/UFC, Fortaleza-CE, Brasil, alcionegf@hotmail.com
} 


\section{Introdução}

A agricultura irrigada vem se desenvolvendo consideravelmente nos últimos anos em todo o país, especialmente na região Nordeste, destacando as culturas da uva e manga, no Vale do São Francisco e melão e banana, no Rio Grande do Norte, contribuindo significativamente no saldo da balança comercial, com as exportações (MAIA et al., 2010).

O Rio Grande do Norte, sobretudo a região do agro-pólo Assu-Mossoró-Baraúna, tem se destacado como principal região produtora de melões do país devido às condições edafoclimáticas e disponibilidade de água superficial e subterrânea (GURGEL et al., 2008). Mesmo assim, observa-se que os consumidores são cada vez mais exigentes quanto aos "tipos" e à qualidade, sendo a firmeza da polpa e o conteúdo de sólidos solúveis (SS), os parâmetros mais observados, além da avaliação da aparência externa e interna (MENEZES et al., 2001). Portanto, introduziu-se a cobertura do solo com filmes plásticos no agro-pólo Assu-Mossoró-Baraúna como uma forma de aumentar a produtividade e melhorar a qualidade dos frutos, bem como reduzir o consumo de água.

O uso da cobertura do solo apresenta como vantagens, redução das perdas de nutrientes por lixiviação, incrementa a concentração de $\mathrm{CO}_{2}$ no ar e ao redor das plantas, acelera o desenvolvimento levando a uma colheita mais precoce, melhora a higiene e qualidade dos frutos, controla doenças e ervas daninhas, melhora a aparência dos frutos, aumenta a produtividade (SAMPAIO; ARAÚJO, 2001) e os teores de sólidos solúveis dos frutos (BRADENBERGER; WIENDENFELD, 1997), além de aumentar também a tolerância ao uso de água de baixa qualidade na irrigação (NASCIMENTO et al., 2000). Como desvantagens, têm-se o elevado custo e a falta de conhecimento detalhado para manejar a irrigação, tanto na estimativa da evapotranspiração para essas condições, quanto na definição de sua freqüência (MARTINS, 1998; SILVA et al., 2005).

Quando se utiliza cobertura plástica espera-se uma redução da necessidade hídrica da cultura pela não evaporação da superfície do solo (ALLEN et al., 1998) entretanto, o maior crescimento da planta, observado com o acúmulo de matéria seca, pode aumentar a demanda hídrica, em relação ao sistema de produção convencional (COSTA et al., 2002). Por isso, torna-se necessário, manejar a irrigação adequadamente para atender às necessidades da cultura e obter maior retorno econômico (AZEVEDO et al., 2005).

$\mathrm{O}$ aumento da temperatura do solo resulta de um balanço de energia que atinge a superfície e a quantidade perdida na forma de calor por convecção, radiação e evaporação. A cobertura plástica é fator primordial para reduzir perdas de calor, sendo o filme transparente o que promove maior aumento da temperatura do solo, seguido pelos filmes preto, laranja, verde, violeta e branco-opaco (TSEKLEEV et al., 1993). Os filmes branco-opaco e prateados, em razão de promoverem menor aquecimento do solo, são ideais para regiões quentes. O movimento da água no solo depende da temperatura, sendo esta, bastante influenciada pela cor da cobertura.

Diversos tipos de filmes são utilizados para cobertura do solo, como os transparentes, os de coloração preta e os de dupla face, os quais dependendo da coloração e da opacidade, apresentam diferentes capacidades de transmitir radiações caloríficas e visíveis (SGANZERLA, 1991).

Objetivou-se com este trabalho avaliar a produção e a qualidade dos frutos de melão amarelo irrigado com diferentes lâminas de irrigação e cultivado em solo coberto com diferentes tipos de filmes de polietileno, comparado ao cultivo sem cobertura.

\section{Material e métodos}

O experimento foi conduzido no período de setembro a dezembro de 2008, na Fazenda WG Fruticultura, localizada em Baraúna, RN, cujas coordenadas geográficas são: $5^{\circ} 04^{\prime} 44^{\prime}$ ' S, 37³7’26” W, em um CAMBISSOLO Háplico franco-argilo-arenoso. Durante o preparo do solo foi feita uma subsolagem, seguido por sulcamento a 0,2 $\mathrm{m}$ de profundidade. Em seguida foi aplicado na fundação a formulação 18-72-30 e 19,5 $\left(\mathrm{kg} \mathrm{ha}^{-1}\right)$ de $\mathrm{N}, \mathrm{P}_{2} \mathrm{O}_{5}, \mathrm{~K}_{2} \mathrm{O}$ e $\mathrm{CaO}$, respetivamente.

Os tratamentos consistiram da combinação de quatro lâminas de irrigação as quais foram distribuídas ao longo do ciclo de acordo com o Kc adotado em cada fase fenológica (FIG. 1) L1 - 452; L2 - 411; L3 - 368; L4 - 329 mm (sendo L1 a lâmina padrão utilizada pelos produtores, determinada pela metodologia do Kc dual da FAO) e as demais corresponderam, respectivamente, a 0,$91 ; 0,81$ e 0,72 da lâmina padrão, resultante da redução da lâmina de irrigação entre a $5^{\mathrm{a}}$ e $10^{\mathrm{a}}$ semana após a semeadura) e quatro tipos de cobertura do solo (três filmes de polietileno dupla face de 25 micras, F1 - filme plástico branco-preto, F2 - filme plástico prata-preto, F3- filme plástico preto-preto) e SF - área sem cobertura com filme plástico, totalizando 16 tratamentos.

O manejo da irrigação foi realizado com base na estimativa da evapotranspiração da cultura, calculada através do método de Penman Monteith, proposto pela FAO 56 (ALLEN et al., 2006), para isso utilizou-se os dados da estação meteorológica do INMET, instalada na comunidade do Pau Branco zona rural de Mossoró, 30 km de distância da área experimental. 
Lâmina de irrigação ao longo do ciclo

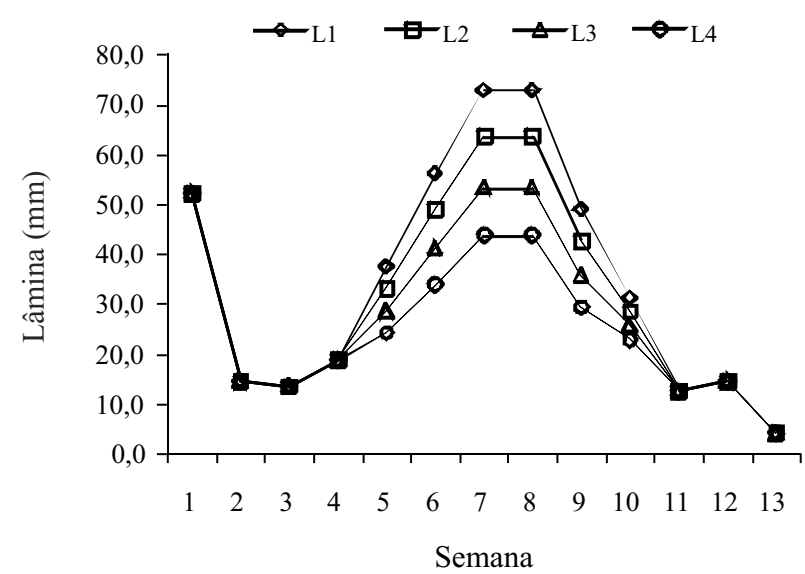

Figura 1 - Distribuição das lâminas de irrigação semanais ao longo ciclo, para os diferentes níveis de lâminas

O delineamento utilizado foi em blocos casualizados, com parcelas subdivididas 4 × 4 e quatro repetições. As lâminas de irrigação foram dispostas nas parcelas e os tipos de filmes de plástico nas sub-parcelas. Cada unidade experimental foi constituída por quatro fileiras de plantas de $5 \mathrm{~m}$ de comprimento, totalizando uma área experimental total de $2560 \mathrm{~m}^{2}$.

A segunda parte dos fertilizantes foi aplicada em fertirrigação e parcelada por fase fenológica (TAB. 1), conforme a marcha de absorção dos nutrientes aplicandose durante o ciclo da cultura as seguintes quantidades de nutrientes $\left(\mathrm{kg} \mathrm{ha}^{-1}\right): \mathrm{N}-98,87 ; \mathrm{P}_{2} \mathrm{O}_{5}-148,31 ; \mathrm{K}_{2} \mathrm{O}$ - 317,78; $\mathrm{CaO}$ - 14,98; $\mathrm{MgO}$ - 1,89; B-0,38; Fe- 0,53; Mn- 0,26; Mo- 0,07; Zn - 0,49, cujas fontes foram uréia, cloreto de potássio, monofosfato amônico e parte da linha de fertilizantes KSC.

O plantio foi realizado diretamente no campo no espaçamento de 2,0 x 0,3 m, utilizando a cultivar de melão, híbrido F1 Mandacaru.

Utilizou-se um sistema de irrigação por gotejamento com emissores espaçados de 2,0 x 0,4 m e a vazão de $1,67 \mathrm{~L} \mathrm{~h}^{-1}$. As lâminas de irrigação aplicadas nas parcelas foram controladas pelo tempo de irrigação, utilizando-se registros.

O controle fitossanitário foi feito para controlar as principais pragas, mosca minadora (Liriomyza sp.) e mosca branca (Bemisia tabaci), e doenças como Oídio, comuns na região; fazendo uso dos seguintes príncipios ativos: thiacloprid $\left(200 \mathrm{ml} \mathrm{ha}^{-1}\right)$, acetamiprido $\left(300 \mathrm{~g} \mathrm{ha}^{-1}\right)$, deltametrina (150 $\left.\mathrm{ml} \mathrm{ha}^{-1}\right)$, cyromazina $\left(120 \mathrm{ml} \mathrm{ha}^{-1}\right)$, abamectina (400 $\mathrm{ml} \mathrm{ha}^{-1}$ ) e azoxystrobina (1280 $\left.\mathrm{g} \mathrm{ha}^{-1}\right)$. todos específicos para a cultura do meloeiro.

Determinou-se aos 22 DAS, por amostragem numa área de $0,5 \mathrm{~m}^{2}$ por parcela $(1,0 \mathrm{~m}$ de fileira $\mathrm{x} 0,5 \mathrm{~m}$ de largura), a infestação de plantas daninhas. Após a coleta das plantas daninhas na área especificada, as mesmas foram postas para secar em estufa a $70{ }^{\circ} \mathrm{C}$ e determinou-se a massa seca. Aos 26 DAS realizaram-se uma capina com enxada nas parcelas sem cobertura, e entre canteiros das parcelas com cobertura plástica.

Como os diferentes tipos de filmes plásticos utilizados nesse experimento, podem proporcionar albedos e crescimento das plantas diferentes, alterando a evapotranspiração da cultura, o monitoramento da umidade do solo medido por meio da tensão, pode fornecer informações aproximadas da real necessidade hídrica das plantas quando cultivas sobre uso de filme plástico. Assim, mediu-se a tensão da água do solo, utilizando tensiômetros de cápsulas porosas, acopladas a tensímetro digital que utilizam transdutores de pressão. Para isso, instalou-se aos 21 DAS no bloco II, representando o que ocorreria nos demais blocos, uma bateria de três tensiômetros a 0,$15 ; 0,30$ e $0,45 \mathrm{~m}$ de profundidade em cada tratamento para se fazer o monitoramento semanal da tensão da água do solo, obtida a partir das leituras realizadas três vezes por semana.

Para estudo da variável tensão, utilizou-se o delineamento em blocos casualizados, com parcelas subdivididas $4 \times 4$. As quatro lâminas de irrigação foram dispostas nas parcelas e os quatro tipos de filmes plástico nas sub-parcelas, totalizando 16 tratamentos, e oito repetições, sendo os blocos representados pelas oito semanas de monitoramento. Para isso, utilizou-se a média das medições de tensão obtidas no perfil de 0,15 a $0,45 \mathrm{~m}$.

Tabela 1 - Distribuição \% dos nutrientes aplicados em fertirrigação na cultura do melão amarelo por fase fenológica

\begin{tabular}{crrrrrrrrrrr}
\hline Idade & \multicolumn{1}{c}{$\mathrm{N}$} & \multicolumn{1}{c}{$\mathrm{P}_{2} \mathrm{O}_{5}$} & \multicolumn{1}{c}{$\mathrm{K} 2 \mathrm{O}$} & $\mathrm{Ca}$ & \multicolumn{1}{c}{$\mathrm{Mg}$} & \multicolumn{1}{c}{$\mathrm{B}$} & $\mathrm{Cu}$ & $\mathrm{Fe}$ & $\mathrm{Mn}$ & $\mathrm{Mo}$ & $\mathrm{Zn}$ \\
\hline (dias) & & & & & \multicolumn{1}{c}{$\%$} & & & & & \\
\hline $0-25$ & 21,25 & 33,66 & 4,71 & 24,30 & 0,00 & 15,68 & 23,90 & 0,00 & 41,10 & 22,40 & 16,27 \\
$26-35$ & 27,43 & 3,56 & 17,54 & 44,86 & 100,00 & 15,16 & 44,02 & 100,00 & 3,77 & 48,28 & 33,15 \\
$36-55$ & 48,54 & 56,11 & 56,13 & 30,84 & 0,00 & 56,72 & 32,07 & 0,00 & 55,14 & 28,52 & 42,44 \\
$56-70$ & 2,77 & 6,67 & 21,62 & 0,00 & 0,00 & 12,44 & 0,00 & 0,00 & 0,00 & 0,81 & 8,14 \\
\hline
\end{tabular}


Ao final do ciclo foram realizadas duas colheitas: a primeira aos 71 DAS e a segunda aos 86 DAS. Os frutos foram selecionados e classificados nas categorias exportação (atendem às exigências de qualidade interna e aparência externa determinadas pelos importadores), mercado interno (não atendem às exigências de qualidades determinadas pelos importadores, mas atendem às especificações dos consumidores brasileiros) e descartados (são frutos que apresentam irregularidades - como deformados, brocados, queimados pelo sol e com virose, e por isso são descartados). Em seguida, foi feito a medição dos parâmetros de produção, produtividade e número de frutos.

$\mathrm{Na}$ primeira colheita, foram separados dois frutos de cada parcela (um grande, representando os frutos destinados ao mercado nacional e um fruto pequeno, representado os frutos destinados ao mercado externo) para determinação de sólidos solúveis ( ${ }^{\circ}$ brix), e peso médio dos frutos por categoria. $\mathrm{O}^{\circ}$ brix foi determinado por refratômetro digital em duas fatias por fruto, e em seguida obteve-se a média aritmética. Na análise dos resultados, foi feita uma análise de variância e, posterior obtenção das equações de regressão para as variáveis quantitativas (lâminas de irrigação). Empregou-se o Teste de Tukey a $5 \%$ de probabilidade, para as variáveis qualitativas (com ou sem cobertura plástica).

\section{Resultados e discussão}

A utilização do filme plástico reduziu significativamente a infestação de plantas daninhas, quando comparado ao plantio sem cobertura, entretanto, essa diferença não pôde ser verificada entre os tipos de filme plástico (TAB. 2).

Observou-se efeito significativo $(\mathrm{p}<0,01)$ da utilização do filme plástico nos parâmetros produção e número de frutos, tanto para os destinados ao mercado externo como para o mercado interno. Não observou-se efeito da lâmina de irrigação quanto à produção e número

Tabela 2 - Valores médios de massa seca de plantas daninhas (MSPD) aos 22 DAS e \% de redução devido à utilização dos filmes plásticosTratamento

\begin{tabular}{lcl}
\hline \multicolumn{1}{c}{ Tratamento } & MSPD $\left(\mathrm{kg} \mathrm{ha}^{-1}\right)$ & Redução\% \\
\hline F1 - branco & $25,96 \mathrm{~b}$ & $-994,8$ \\
F2 - prata & $28,35 \mathrm{~b}$ & $-902,5$ \\
F3 - preto & $18,72 \mathrm{~b}$ & $-1418,2$ \\
SF - sem & $284,21 \mathrm{a}$ & \\
\hline
\end{tabular}

Para comparação, médias seguidas da mesma letra não diferem entre si ao nível de 5\% de significância pelo teste de Tukey de frutos, bem como da interação dos fatores lâminas de irrigação e coberturas de filmes plásticos para as variáveis estudadas (TAB. 3).

Observou-se altos valores de CV tanto na produção quanto no número de frutos para mercado interno, possivelmente devido a erro do classificador (por ser subjetivo) quanto aos frutos destinados a esse mercado, pois se aceita quase tudo, diferente do mercado externo que é bem mais seletivo. Quanto aos CV das produções de uma forma geral, em condições de campo normalmente fica entre 15 e $20 \%$. No experimento, atribui-se à elevada infestação de pragas e doenças comuns na região no período em que o mesmo foi conduzido, mesmo com as pulverizações para controle, estas provocam danos como diminuição da área fotossintética da cultura, e também à infestação de ervas daninhas no tratamento sem cobertura plástica, que ocorrem em reboleiras, aumentando o erro experimental.

As variáveis massas, e obrix médio dos frutos destinados à exportação $\mathrm{e}^{\mathrm{o}}$ brix médio foram influenciados significativamente $(\mathrm{p}<0,05)$ pela lâmina de irrigação, confirmando a importância do manejo da água na padronização dos tamanhos dos frutos destinados à exportação, como também no ${ }^{\circ}$ brix dos mesmos (TAB. 4).

A análise de regressão mostrou efeito significativo das lâminas de irrigação para massa média dos frutos, destinados à exportação, ao mercado interno, massa média $\mathrm{e}^{\mathrm{o}}$ brix. Para massa média, o modelo ajustado foi polinônio de segudo grau com coeficientes de determinação e significância, $\mathrm{R}^{2}=0,87^{* *}$, enquanto que para ${ }^{\circ}$ brix médio, o modelo ajustado apresentou efeito linear crescente com $\mathrm{R}^{2}=0,76^{*}$ (FIG. 2).

Observou-se diferença significativa $(\mathrm{p}<0,05)$ entre os tratamentos onde foi utilizado o filme plástico em relação ao solo descoberto para produtividade e número de frutos em todas as categorias de classificação dos frutos, entretanto entre os tratamentos com filme plástico não houve diferença (TAB. 5).

Quando foi utilizado filme plástico no solo observou-se um aumento médio na produtividade dos frutos de 126; 151 e 133\%, nas categorias exportação mercado interno e total comercializável respectivamente, em relação ao plantio sem utilização de filme plástico. Medeiros et al. (2006), observou aumentos de 38,96\% trabalhando com híbridos de melão cantaloupe; e Bradenberger e Wiendenfeld (1997), verificaram incremento na produção em média, de $42 \%$.

Quanto aos tipos de filme plástico, observaramse incrementos de produtividade de $141,64 \% ; 113,33 \%$ e $145,62 \%$ para o filme de cor branca, prata e preto respectivamente, quando comparado ao plantio sem filme plástico. Morais et al. (2008), quando testou filmes plásticos 
Tabela 3 - Resumo da análise de variância para aspectos produtivos do melão destinados à exportação (Export.) e ao mercado interno (M.I.), Baraúna, 2008

\begin{tabular}{|c|c|c|c|c|c|c|c|}
\hline \multirow{3}{*}{ F.V. } & \multirow{3}{*}{ G.L. } & \multicolumn{3}{|c|}{ Produção } & \multicolumn{3}{|c|}{$\mathrm{N}^{\mathrm{o}}$ frutos } \\
\hline & & Export. & M.I. & Total & Export. & M.I. & Total \\
\hline & & \multicolumn{6}{|c|}{ Estatística F } \\
\hline Blocos & 3 & $3,12 *$ & $0,88^{\mathrm{ns}}$ & $2,65^{\mathrm{ns}}$ & $4,66 * *$ & $1,11^{\mathrm{ns}}$ & $3,57^{*}$ \\
\hline Lâminas & 3 & $0,37^{\mathrm{ns}}$ & $1,01^{\mathrm{ns}}$ & $1,04^{\mathrm{ns}}$ & $0,83^{\mathrm{ns}}$ & $0,82^{\mathrm{ns}}$ & $0,9^{\text {ns }}$ \\
\hline Ef. Linear & 1 & $0,57^{\mathrm{ns}}$ & $0,01^{\mathrm{ns}}$ & $0,27^{\mathrm{ns}}$ & $2,07^{\mathrm{ns}}$ & $0,14^{\mathrm{ns}}$ & $1,46^{\mathrm{ns}}$ \\
\hline Ef. Quadr. & 1 & $0,47^{\mathrm{ns}}$ & $2,78^{\mathrm{ns}}$ & $2,59^{\mathrm{ns}}$ & $0,16^{\mathrm{ns}}$ & $0,79^{\mathrm{ns}}$ & $0,07^{\mathrm{ns}}$ \\
\hline Erro (A) & 9 & & & & & & \\
\hline Filme & 3 & $30,59 * *$ & $20,16^{* *}$ & $42,88 * *$ & $22,56^{* *}$ & $13,96 * *$ & $32,35 * *$ \\
\hline Filme x Lâm. & 9 & $0,74^{\mathrm{ns}}$ & $2,07^{\mathrm{ns}}$ & $1,00^{\mathrm{ns}}$ & $0,79^{\text {ns }}$ & $1,27^{\mathrm{ns}}$ & $0,96^{\mathrm{ns}}$ \\
\hline Erro (B) & 36 & & & & & & \\
\hline CV (A) & & 27,60 & 53,22 & 25,21 & 28,97 & 56,32 & 29,34 \\
\hline CV (B) & & 24,30 & 31,70 & 20,84 & 22,73 & 31,90 & 19,43 \\
\hline
\end{tabular}

Tabela 4 - Resumo da análise de variância para parâmetros de qualidade dos frutos do melão destinados à exportação (Export.) e ao mercado interno (M.I.) e média geral, Baraúna, 2008

\begin{tabular}{|c|c|c|c|c|c|c|c|}
\hline \multirow{3}{*}{ F.V. } & \multirow{3}{*}{ G.L. } & \multicolumn{3}{|c|}{ Massa dos frutos } & \multicolumn{3}{|c|}{${ }^{\circ}$ Brix } \\
\hline & & Export. & M.I. & Média & Export. & M.I. & Média \\
\hline & & \multicolumn{6}{|c|}{ Estatística F } \\
\hline Blocos & 3 & $1,51^{\mathrm{ns}}$ & $7,21^{\mathrm{ns}}$ & $5,75 * *$ & $2,39^{\mathrm{ns}}$ & $7,21 * *$ & $2,93^{*}$ \\
\hline Lâminas & 3 & $2,85^{\mathrm{ns}}$ & $1,86^{\mathrm{ns}}$ & $9,49 * *$ & $6,12^{* *}$ & $1,86^{\mathrm{ns}}$ & $3,63^{*}$ \\
\hline Ef. Linear & 1 & $2,62^{\text {ns }}$ & $3,28^{\mathrm{ns}}$ & $7,81 *$ & $17,39 * *$ & $1,86^{\mathrm{ns}}$ & $8,24 *$ \\
\hline Ef. Quadr. & 1 & $5,84^{*}$ & $5,90^{*}$ & $16,92 * *$ & $0,92^{\text {ns }}$ & $2,29^{\mathrm{ns}}$ & $1,93^{\mathrm{ns}}$ \\
\hline Erro (A) & 9 & & & & & & \\
\hline Filme & 3 & $14,14 * *$ & $2,06^{\mathrm{ns}}$ & $25,43 * *$ & $0,45^{\mathrm{ns}}$ & $2,06^{\mathrm{ns}}$ & $1,49^{\mathrm{ns}}$ \\
\hline Filme x Lâm. & 9 & $0,43^{\mathrm{ns}}$ & $1,11^{\mathrm{ns}}$ & $0,90^{\mathrm{ns}}$ & $1,22^{\mathrm{ns}}$ & $2,06^{\mathrm{ns}}$ & $1,50^{\mathrm{ns}}$ \\
\hline Erro (B) & 36 & & & & & & \\
\hline CV (A) & & 11,90 & 10,40 & 8,14 & 8,54 & 10,40 & 8,64 \\
\hline CV (B) & & 9,81 & 11,76 & 7,92 & 14,85 & 11,76 & 8,64 \\
\hline
\end{tabular}

preto e prata na produção da cultivar Goldex, melão amarelo, também observou expressivos incrementos na produção $(82$ e $99 \%$, respectivamente) em relação ao plantio sem filme plástico; bem como Costa (2002), que obteve ganhos de 71\% para o preto e $119 \%$ para o filme prateado, e Câmara et al. (2007) que observou aumento na produtividade dos frutos comercializáveis de 67,$6 ; 90,5 ; 56,4$ e 72,5\% para cobertura do solo com filmes de coloração preta, prata, amarela e marrons com a cultivar Goldex em período chuvoso.

Para Pôrto et al. (2005) e Medeiros et al. (2006) isso se deve aos benefícios do cultivo em solo coberto, pois neste cultivo há menos competição com ervas daninhas, e melhor aproveitamento da água quando comparado com o solo nu, por não se verificar evaporação, mas somente transpiração da planta. Desta forma, as plantas do tratamento com cobertura de solo apresentaram melhores condições para o aproveitamento da água disponível que, ao ser reduzida gradualmente durante a secagem do solo, provavelmente reduz o estresse na planta, fazendo com que obtivesse melhor desenvolvimento, tanto da área foliar quanto da fitomassa, refletindo, diretamente no aumento de produtividade do meloeiro. 


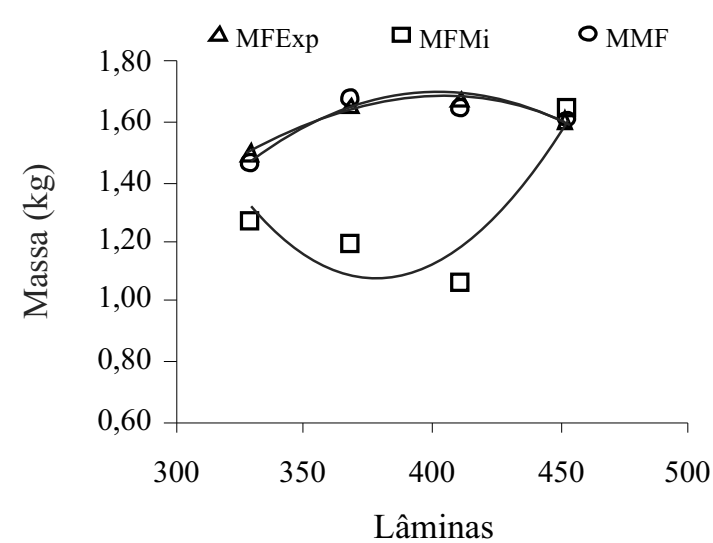

MFExp $=-3,94+0,0279^{\text {ns }} \mathrm{L}-0,0000347 * \mathrm{~L}^{2} \quad \mathrm{R}^{2}=0,99 *$

MFMi $=-7,57+0,0461102^{\mathrm{ns}} \mathrm{L}-0,0000570643 * \mathrm{~L}^{2} \quad \mathrm{R}^{2}=0,64 *$

$\mathrm{MMF}=-4,86+0,0325396 * \mathrm{~L}-0,0000403888^{*} * \mathrm{~L}^{2} \quad \mathrm{R}^{2}=0,87 *$

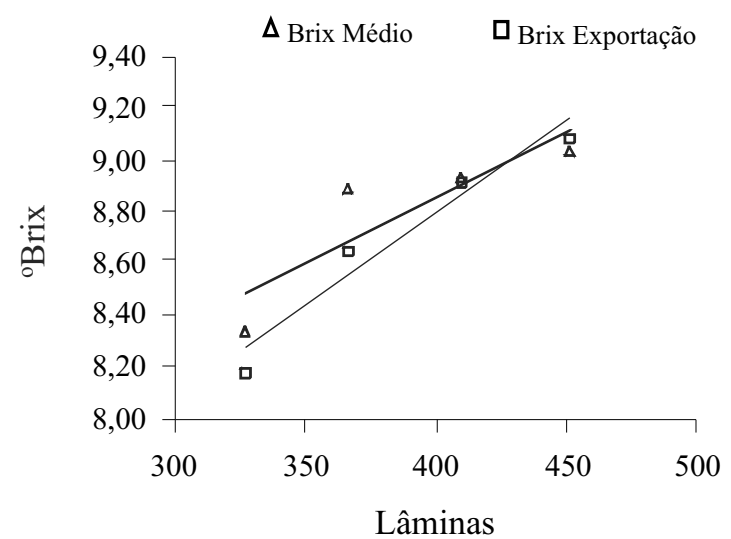

$\operatorname{BFExp}=5,436+0,0084 * * \mathrm{~L} \quad \mathrm{R}^{2}=0,95 * *$

$\mathrm{BMF}=6,52+0,006^{* *} \mathrm{~L} \quad \mathrm{R}^{2}=0,76^{*}$

MFExp - massa média dos frutos exportáveis, MFMi - massa mediados frutos destinados ao mercado interno, MMF - massa média dos frutos, BFExp - 'brix dos frutos exportáveis, BMF - obrix médio dos frutos

Figura 2 - Efeito das lâminas de irrigação na massa média e obrix dos frutos de melão amarelo, em Baraúna - RN, 2008

Tabela 5 - Valores médios e aumento relativo ao plantio sem filme plástico de produtividade e número de frutos de melão amarelo nas categorias: exportação, mercado interno e descartada. Baraúna, 2008

\begin{tabular}{|c|c|c|c|c|c|c|c|}
\hline \multirow{2}{*}{ Tratamentos } & Export* & Aumento & Interno** & Aumento & Total & Aumento & Descarte*** \\
\hline & \multicolumn{7}{|c|}{ Produtividade $\left(\mathrm{Mg} \mathrm{ha}^{-1}\right)$} \\
\hline M1 - branco & $20,26 \mathrm{a}$ & $138,20 \%$ & $8,76 \mathrm{a}$ & $149,99 \%$ & $29,02 \mathrm{a}$ & $141,64 \%$ & $6,00 \mathrm{a}$ \\
\hline M2 - prata & $17,20 \mathrm{a}$ & $102,24 \%$ & $8,42 \mathrm{a}$ & $140,24 \%$ & $25,62 \mathrm{a}$ & $113,33 \%$ & $5,70 \mathrm{ab}$ \\
\hline M3 - preto & $20,32 \mathrm{a}$ & $138,85 \%$ & $9,18 \mathrm{a}$ & $162,06 \%$ & $29,50 \mathrm{a}$ & $145,62 \%$ & $6,58 \mathrm{a}$ \\
\hline SM - sem & $8,51 \mathrm{~b}$ & & $3,50 \mathrm{~b}$ & & $12,01 \mathrm{~b}$ & & $3,20 \mathrm{~b}$ \\
\hline \multicolumn{8}{|c|}{ Número de frutos (unid. ha ${ }^{-1}$ ) } \\
\hline M1 - branco & $11758 \mathrm{a}$ & $91,71 \%$ & $5039 \mathrm{a}$ & $95,45 \%$ & $16797 \mathrm{a}$ & $92,83 \%$ & $4727 \mathrm{a}$ \\
\hline M2 - prata & $11016 \mathrm{a}$ & $79,61 \%$ & $5547 \mathrm{a}$ & $115,16 \%$ & $16563 \mathrm{a}$ & $90,13 \%$ & $5156 \mathrm{ab}$ \\
\hline M3 - preto & $11992 \mathrm{a}$ & $95,53 \%$ & $5313 \mathrm{a}$ & $106,06 \%$ & $17305 \mathrm{a}$ & $98,65 \%$ & $5664 \mathrm{a}$ \\
\hline SM - sem & $6133 b$ & & $2578 \mathrm{~b}$ & & $8711 \mathrm{a}$ & & $2656 \mathrm{~b}$ \\
\hline \multicolumn{8}{|c|}{ Lâmina (mm) } \\
\hline L1 - 452 & $9571 \mathrm{a}$ & & $3984 \mathrm{a}$ & & $13555 \mathrm{a}$ & & $5.703 \mathrm{ab}$ \\
\hline L2 - 411 & $10078 \mathrm{a}$ & & $5391 \mathrm{a}$ & & $15469 \mathrm{a}$ & & $5.898 \mathrm{a}$ \\
\hline L3 - 368 & 10078 a & & $4414 \mathrm{a}$ & & $14492 \mathrm{a}$ & & $3.476 \mathrm{ab}$ \\
\hline L4 - 329 & $11171 \mathrm{a}$ & & $4687 \mathrm{a}$ & & $15859 \mathrm{a}$ & & $3.125 \mathrm{a}$ \\
\hline
\end{tabular}

Para comparação na mesma coluna, médias seguidas da mesma letra não diferem entre si ao nível de 5\% de significância pelo teste de Tukey; Valores em porcentagem referem-se ao aumento médio com número de frutos totais na mesma linha. *Export- frutos classificados na categoria exportação; **interno frutos classificados na categoria mercado interno; ***Descart - frutos refugados, destinados para alimentação animal

Observou-se efeito significativo do fator lâmina de irrigação somente no número de frutos refugados, onde as lâminas L2 e L1 apresentaram um acréscimo de $76 \%$ em média. A redução da lâmina d'água em até $28 \%$ não alterou nenhuma variável de produção de forma significativa. Portanto, é recomendada a redução da lâmina de irrigação por questões de economia de água e redução de custo.

Observou-se uma tendência de aumento da produção descartada nos tratamentos onde foram 
utilizadas as coberturas com filmes plásticos. Isto é justificado pela maior frutificação obtida com o uso da tecnologia da cobertura do solo com esses filmes. A experimentação de dosagens de nutrientes poderia concluir melhor essa tendência, caso estes frutos viessem a se tornar comercializáveis com alguma combinação nutricional. A baixa produtividade observada no tratamento sem filme plástico pode ser atribuída em grande parte à competição do meloeiro com as plantas daninhas.

$\mathrm{Na}$ componente de produção massa dos frutos, observou-se efeito significativo dos tipos de filmes e das lâminas de irrigação em todas as categorias. Os tratamentos com filmes plásticos branco e preto apresentaram um acréscimo médio de $200 \mathrm{~g}$ em relação aos frutos dos tratamentos com filme prata, e $300 \mathrm{~g}$ em relação ao tratamento sem filme plástico. A utilização do filme plástico proporcionou um aumento de $20 \%$ na massa média dos frutos. Não se observou diferença significativa para massa dos frutos entre os tratamentos com filme branco e preto (TAB. 6).

Quanto à lâmina de irrigação, observou-se uma redução média na massa dos frutos de $11 \%$ quando foi utilizada a lâmina L4. Enquanto Negreiros et al. (2005), estudando a cultivar Gold Mine sob três tipos de lâminas e coberturas com filmes de polietileno de diferentes cores obteve massa média dos frutos semelhantes, independentemente da lâmina de irrigação aplicada. É importante salientar que além das cultivares ter sido diferente, o período do trabalho de Negreiros foi de abril a julho de 2002, estação chuvosa, enquanto neste foi de setembro a dezembro de 2008.

Observou-se neste trabalho relato semelhante ao de Taiz e Zeigler (2004) que afirmaram que a redução da área foliar implicou em redução da capacidade fotossintética da planta e, conseqüentemente, menor quantidade de carboidratos para os frutos. Portanto, possivelmente as melhores condições de umidade e de sanidade das plantas pelos efeitos das coberturas plásticas, tenham proporcionado estes resultados, quando comparadas com o solo descoberto.

Foi observado efeito significativo das lâminas de irrigação no fator teor de sólidos solúveis ( ${ }^{\circ} \mathrm{brix}$ ), para os frutos destinados ao mercado externo, frutos pequenos. Enquanto que para os frutos mais apreciados pelo consumidor local, que são os frutos grandes, não se observou esse efeito (TAB. 7). Desta forma, é importante salientar a importância dessa pesquisa para o produtor, como uma ferramenta de auxilio de tomada de decisão, quanto à lâmina de irrigação a ser utilizada, de acordo com o mercado ao qual ele pretende destinar sua produção.

Em média, observou-se que à medida que a lâmina aumentou o ${ }^{\circ}$ brix também subiu. Para os frutos grandes não se observou diferença significativa. Mesmo não havendo diferença significativa estatisticamente no teor de sólidos solúveis totais dos tratamentos L1, L2 e L3, tanto para frutos pequenos como para frutos grandes, na prática apenas os frutos obtidos com L1 e L2 estariam dentro das exigências dos importadores, os quais exigem obrix maior que 9,0. Quanto aos tipos de filme plástico, não houve efeito significativo para $\mathrm{o}^{\circ} \mathrm{brix}$.

Em média, o obrix da área foi baixo, podendo ser justificado pela alta incidência de virose (amarelão do melão) e mosca minadora. Conforme Nagata et al., (2003) e Santos et al., (2004), o amarelão pode ocasionar prejuízos na produção e, principalmente, na qualidade dos frutos, pela redução do teor de ${ }^{\circ}$ brix. Isso ocorre devido à redução da

Tabela 6 - Valores médios das massas dos frutos do melão amarelo nas categorias: exportação, mercado interno e total comercial. Baraúna, 2008

\begin{tabular}{lccc}
\hline \multirow{2}{*}{ Tratamentos } & \multicolumn{3}{c}{ Média da massa dos frutos $(\mathrm{kg})$} \\
\cline { 2 - 4 } & Exportação & Interno & Comerc. \\
\hline M1 - branco & $1,74 \mathrm{a}$ & $1,76 \mathrm{a}$ & $1,74 \mathrm{a}$ \\
M2 - prata & $1,58 \mathrm{~b}$ & $1,51 \mathrm{~b}$ & $1,56 \mathrm{~b}$ \\
M3 - preto & $1,71 \mathrm{ab}$ & $1,74 \mathrm{a}$ & $1,72 \mathrm{a}$ \\
SM - sem & $1,41 \mathrm{c}$ & $1,44 \mathrm{~b}$ & $1,40 \mathrm{c}$ \\
\hline & \multicolumn{3}{c}{ Lâmina $(\mathrm{mm})$} \\
\hline L1 (451,9) & $1,60 \mathrm{ab}$ & $1,65 \mathrm{ab}$ & $1,65 \mathrm{a}$ \\
L2 $(411,1)$ & $1,67 \mathrm{a}$ & $1,63 \mathrm{~b}$ & $1,61 \mathrm{a}$ \\
L3 (368,3) & $1,65 \mathrm{a}$ & $1,79 \mathrm{a}$ & $1,69 \mathrm{a}$ \\
L4 (328,6) & $1,49 \mathrm{~b}$ & $1,38 \mathrm{~b}$ & $1,46 \mathrm{~b}$ \\
\hline
\end{tabular}

Para comparação na mesma coluna, médias seguidas da mesma letra não diferem entre si a 5\% de significância pelo teste de Tukey 
taxa de assimilação líquida do carbono, o que resulta numa diminuição da produção de matéria seca das plantas e, conseqüentemente, da produção de frutos (SANTOS et al., 2004).

Observou-se efeito significativo dos diferentes tipos de filmes plásticos nas diferentes lâminas de irrigação para tensão da água no solo na camada $0-0,45 \mathrm{~m}$.

O tratamento sem filme plástico apresentou, em média, maiores tensões, podendo ser explicado, pela incidência direta dos raios solares sobre o solo e a alta incidência de plantas daninhas neste tratamento, o que favoreceu à evapotranspiração (TAB. 8).

Tabela 7 - Valores médios de teor de sólidos solúveis totais de frutos pequenos e frutos grandes e médio de melão amarelo. Baraúna, 2008

\begin{tabular}{cccc}
\hline \multirow{2}{*}{$\begin{array}{c}\text { Lâmina } \\
(\mathrm{mm})\end{array}$} & \multicolumn{3}{c}{ Teor de sólidos solúveis totais } \\
\cline { 2 - 4 } & $\begin{array}{c}\text { Frutos } \\
\text { pequenos }\end{array}$ & $\begin{array}{c}\text { Frutos } \\
\text { grandes }\end{array}$ & Média \\
\hline L1 (452) & $9,17 \mathrm{a}$ & $9,04 \mathrm{a}$ & $9,11 \mathrm{a}$ \\
L2 (411) & $8,97 \mathrm{a}$ & $9,01 \mathrm{a}$ & $8,99 \mathrm{ab}$ \\
L3 (368) & $8,66 \mathrm{ab}$ & $8,82 \mathrm{a}$ & $8,94 \mathrm{ab}$ \\
L4 (329) & $8,11 \mathrm{~b}$ & $8,49 \mathrm{a}$ & $8,30 \mathrm{~b}$ \\
\hline
\end{tabular}

Para comparação na mesma coluna, médias seguidas da mesma letra não diferem entre si ao nível de 5\% de significância pelo teste de Tukey

Tabela 8 - Média de tensão da água no solo cultivado de melão amarelo. Baraúna, 2008

\begin{tabular}{|c|c|c|c|c|c|}
\hline \multirow[b]{2}{*}{ Tratamentos } & \multicolumn{4}{|c|}{ Tensão (cm ca) } & \multirow[b]{2}{*}{ Média } \\
\hline & $\begin{array}{l}\mathrm{L} 1- \\
451\end{array}$ & $\begin{array}{l}\text { L2 - } \\
411\end{array}$ & $\begin{array}{l}\text { L3 - } \\
368\end{array}$ & $\begin{array}{l}\text { L4 - } \\
329\end{array}$ & \\
\hline F1 - branco & $50,9 \mathrm{ab}$ & $50,8 \mathrm{~b}$ & $63,5 \mathrm{a}$ & $51,7 \mathrm{ab}$ & 54,3 \\
\hline F2 - prata & $46,2 \mathrm{~b}$ & $54,1 \mathrm{~b}$ & $46,8 \mathrm{a}$ & $39,4 \mathrm{~b}$ & 46,6 \\
\hline F3 - preto & $67,4 \mathrm{a}$ & $46,9 \mathrm{~b}$ & $43,9 \mathrm{a}$ & $41,6 \mathrm{~b}$ & 50,0 \\
\hline SF - sem & $65,3 \mathrm{ab}$ & $76,5 \mathrm{a}$ & $63,4 \mathrm{a}$ & $66,1 \mathrm{a}$ & 67,8 \\
\hline Média & 57,5 & 57,1 & 54,5 & 49,7 & 54,7 \\
\hline $\mathrm{CVa}(\%)$ & & & 27,92 & & \\
\hline $\mathrm{CVb}(\%)$ & & & 23,67 & & \\
\hline
\end{tabular}

Mesmo tendo diferença entre as tensões, estas ficaram abaixo da tensão referente à capacidade de campo (101,97 cmc.a.), mostrando que em todos os casos houve uma tendência de percolação (FIG. 3). Observou-se que o tratamento sem filme plástico apresentou maior tensão da água no solo tanto no início como no final do ciclo. Essa característica nesses dois períodos pode ser justificada pela maior incidência de plantas daninhas e pela maior evaporação da água do solo neste tratamento. Nos demais tratamentos, observou-se uma tendência de diminuição da tensão da água no solo provavelmente devido ao acúmulo da lâmina nas camadas mais profundas do solo.
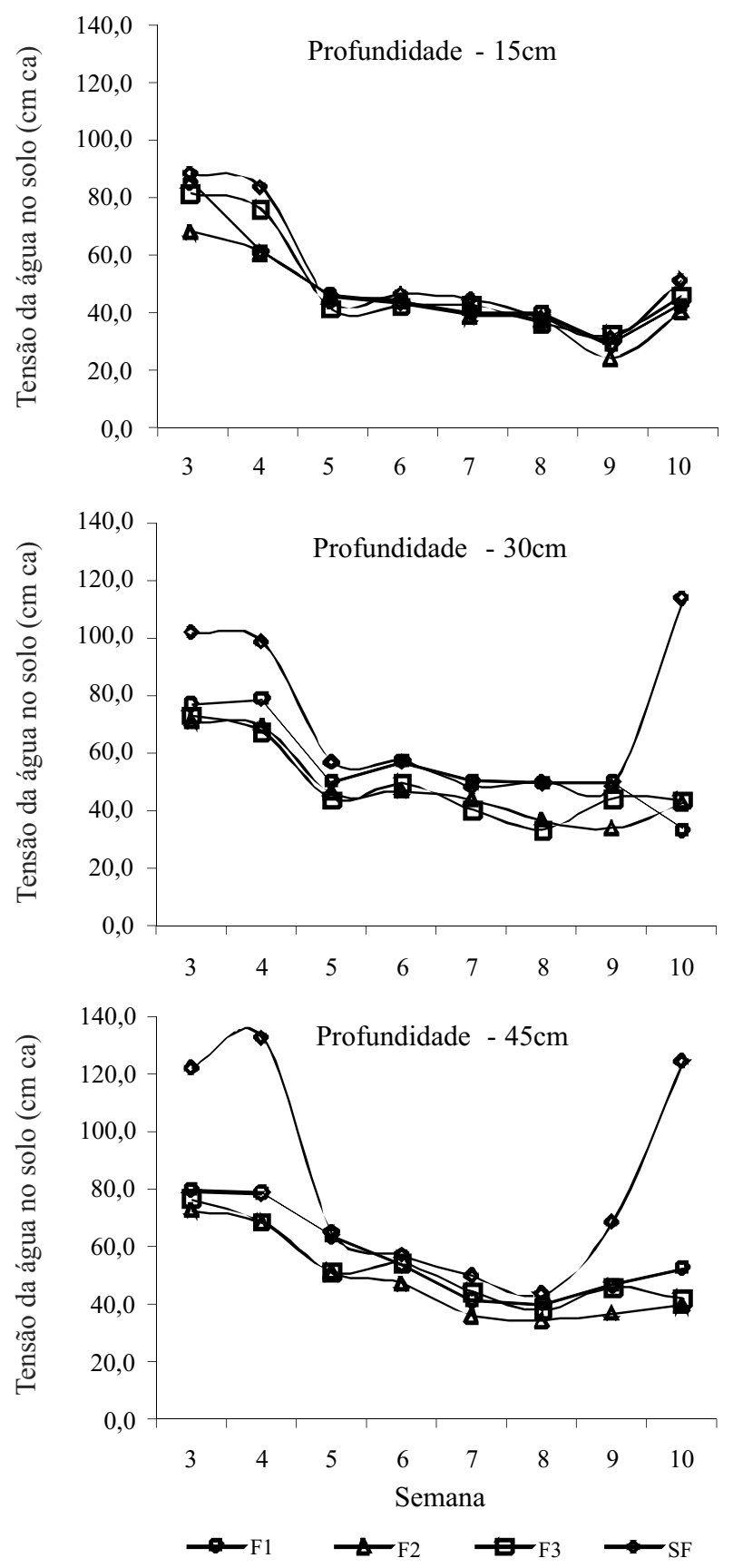

Figura 3 - Monitoramento da tensão da água no solo ao longo do ciclo da cultura para os diferentes tipos de filmes plásticos, F1- filme branco; F2 - filme prata; F3- filme preto; SF - sem filme nas profundidades 15,30 e $45 \mathrm{~cm}$ 
O tratamento com filme preto apresentou efeito significativo quadrático das lâminas de irrigação na tensão da água no solo (FIG. 4). Portanto, à medida que a lâmina de irrigação aumentou observou-se um aumento também na tensão da água no solo. Possivelmente isso se deveu ao aumento no desenvolvimento vegetativo da planta (maior fitomassa), como resposta à maior disponibilidade de água decorrente da utilização do filme plástico, sendo, portanto, necessário maior volume de água pela planta para que a mesma possa demonstrar o seu potencial produtivo. Isso pôde ser comprovada com a maior produtividade observada pelo filme plástico preto.

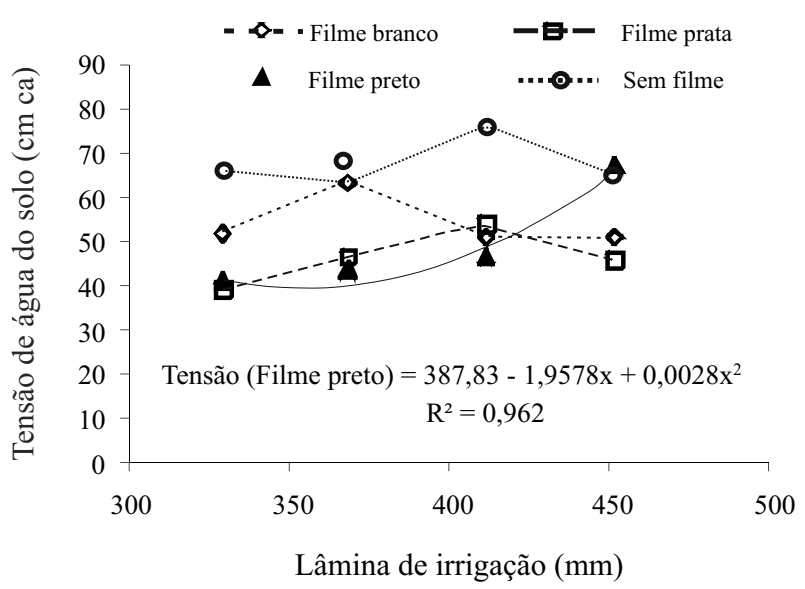

Figura 4 - Monitoramento da tensão da água no solo observada em 4 tipos de cobertura em 4 lâminas de irrigação

\section{Conclusões}

1.A utilização dos filmes plásticos proporcionou um aumento expressivo na produtividade;

2. Não se observou diferença significativa entre os tratamentos com filmes de polietileno em nenhuma categoria de frutos, relacionado à produtividade;

3. A lâmina padrão de $452 \mathrm{~mm}$, utilizada pela fazenda no período de setembro a dezembro, pode ser reduzida em até $28 \%$ sem alterar a produção e em $20 \%$ sem diminuir o peso médio dos frutos;

4.A utilização dos filmes plásticos proporcionou um aumento médio de $20 \%$ no peso médio dos frutos, embora com os filmes plásticos preto e branco sendo superior ao prata;

5.A redução da lâmina de irrigação proporcionou diminuição dos sólidos solúveis apenas dos frutos de melão menores.

\section{Agradecimentos}

À WG fruticultura pela permissão para desenvolver o trabalho em suas dependências e apoio e à Electro plástic ${ }^{\circledR}$ pelo financiamento do custeio do projeto de pesquisa.

\section{Referências}

ALLEN, R. G. et al. Crop evapotranspiration: guidelines for computing crop water requirements. Rome: FAO, 1998. 300 p. (FAO, Irrigation and Drainage Paper, 56).

ALLEN, R. G. et al. Evapotranspiration del cultivo: guias para la determinación de los requerimientos de agua de los cultivos. Roma: FAO, 2006, 298 p. (FAO, Estudio Riego e Drenaje Paper, 56).

AZEVEDO, B. M. et al. Efeitos de níveis de irrigação na cultura da melancia. Revista Cência Agronômica, v. 36, n. 01, p. 9-15, 2005.

BRADENBERG, L.; WIENDEFELD, B. Physical characteristics of mulches and their impact on crop response and profitability in muskmelon production. HortTechnology, v. 07, n. 02, p. 165-169, 1997.

CÂMARA, M. J. T. et al. Produção e qualidade de melão amarelo influenciado por coberturas do solo e lâminas de irrigação no período chuvoso. Ciência Rural, v. 37, n. 01, p. 58-63, 2007.

COSTA, F. A. et al. Rendimento de melão cantaloupe em diferentes coberturas de solo e lâminas de irrigação. Caatinga, v. 15, n. 01/02, p. 49-55, 2002.

COSTA, F. A. Cobertura do solo e lâmina de irrigação no rendimento e qualidade do melão "Gold Mine" cultivado no período chuvoso. Mossoró, 2002. 56 f. Dissertação (Mestrado em Agronomia: Fitotecnia) - Escola Superior de Agricultura de Mossoró, Mossoró.

GURGEL, M. T. et al. Nutrição de cultivares de meloeiro irrigadas com águas de baixa e alta salinidade. Caatinga, v. 21, n. 05 , p. 36-43, 2008. Número especial.

MAIA, C. E. et al. Dimensões de bulbo molhado na irrigação por gotejamento superficial. Revista Ciência Agronômica, v. 41, n. 01, p. 149-158, 2010.

MARTINS, S. R. et al. Produção de melão em função de diferentes sistemas de condução de plantas em ambiente protegido. Horticultura Brasileira, v. 16, n. 01, p. 24-30, 1998.

MEDEIROS, J. F. et al. Crescimento e produção do melão cultivado sob cobertura de solo e diferentes freqüências de irrigação. Revista Brasileira de Engenharia Agrícola e Ambiental, v. 10, n. 04, p. 792-797, 2006.

MENEZES, J. B. et al. Armazenamento de dois genótipos de melão amarelo sob condições ambientais. Horticultura Brasileira, v. 19, n. 01 , p. 42-49, 2001.

MORAIS, E. R. C. et al. Crescimento e produtividade do meloeiro Goldex influenciado pela cobertura do solo. Scientia Agraria, v. 09, n. 02, p. 129-137, 2008. 
NAGATA, T. et al. Isolation of a novel Carlavirus from melon in Brazil. Fitopatologia Brasileira, v. 28, p. 251-252, 2003. Suplemento.

NASCIMENTO, I. B. et al. Desenvolvimento vegetativo do melão cultivado sob diferentes intensidades de preparo de solo com e sem mulching. In: CONGRESSO BRASILEIRO DE ENGENHARIA AGRÍCOLA, 29. Fortaleza, Anais... Ceará: SBEA, 2000. CD-ROM.

NEGREIROS, M. Z. et al. Rendimento e qualidade do melão sob lâminas de irrigação e cobertura do solo com filmes de polietileno de diferentes cores. Horticultura Brasileira, v. 23, n. 03, p. 773-779, 2005.

PÔRTO, D. R. Q. et al. Crescimento do melão 'Torreon' cultivado em diferentes coberturas de solo e lâminas de irrigação. Caatinga, v. 18, n. 04, p. 232-237, 2005.

SAMPAIO, R. A.: ARAÚJO, W. F. Importância da cobertura plástica do solo sobre o cultivo de hortaliças. Agropecuária Técnica, v. 22, n. 01/02, p. 1-12, 2001.
SANTOS, A. A. et al. Efeito do amarelão e da mosca-branca na fixação de $\mathrm{CO}_{2}$, na produção e no teor de sólidos solúveis totais de frutos do meloeiro. Revista Ciência Agronômica, v. 35, p. 214-219, 2004. Número especial.

SGANZERLA, E. Nova agricultura: a fascinante arte de cultivar com os plásticos. 4. ed. Porto Alegre: Plasticultura Gaúcha, 1991. 303 p.

SILVA, M. C. C. et al. Produtividade de frutos do meloeiros sob diferentes níveis de salinidade da água de irrigação, com e sem cobertura do solo. Horticultura Brasileira, v. 23, n. 02, p. 202-205, 2005.

TAIZ, L.; ZEIGER, E. Fisiologia vegetal. Porto Alegre: Artmed, 2004. p. 449-484.

TSEKLEEV, G. et al. Influence of photo-selective mulch films on tomatoes in greenhouses. Plasticulture, v. 95, p. 45-49, 1993. 